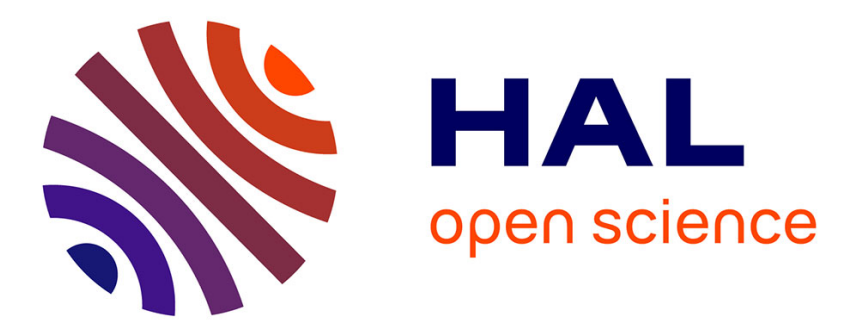

\title{
Influence of a treated kaolinite on the thermal degradation and flame retardancy of poly(methyl methacrylate)
}

H. Vahabi, M. Batistella, B. Otazaghine, C. Longuet, Laurent Ferry, José-Marie Lopez-Cuesta

\section{To cite this version:}

H. Vahabi, M. Batistella, B. Otazaghine, C. Longuet, Laurent Ferry, et al.. Influence of a treated kaolinite on the thermal degradation and flame retardancy of poly(methyl methacrylate). Applied Clay Science, 2012, 70, pp.58-66. 10.1016/j.clay.2012.09.013 . hal-00825565

\section{HAL Id: hal-00825565 https://hal.science/hal-00825565}

Submitted on 9 Jul 2021

HAL is a multi-disciplinary open access archive for the deposit and dissemination of scientific research documents, whether they are published or not. The documents may come from teaching and research institutions in France or abroad, or from public or private research centers.
L'archive ouverte pluridisciplinaire HAL, est destinée au dépôt et à la diffusion de documents scientifiques de niveau recherche, publiés ou non, émanant des établissements d'enseignement et de recherche français ou étrangers, des laboratoires publics ou privés. 


\title{
Influence of a treated kaolinite on the thermal degradation and flame retardancy of poly(methyl methacrylate)
}

\author{
H. Vahabi, M.A. Batistella, B. Otazaghine *, C. Longuet, L. Ferry, R. Sonnier, J.-M. Lopez-Cuesta \\ Ecole des Mines d'Alès, Centre des Matériaux (CMGD), Pôle Matériaux Polymères Avancés, 6 Avenue de Clavières, 30319 Ales cedex, France
}

\begin{abstract}
A B S T R A C T
Modified kaolinite poly(methyl methacrylate) nanocomposites were prepared using successively in situ polymerization and melt blending methods. Pristine kaolinite (Kaol) was intercalated using two organic molecules dimethyl sulfoxide (DMSO) and dodecylamine. This treated kaolinite (TKaol) was exfoliated via in situ polymerization of MMA. The prepared blends were extruded with a commercially available PMMA and then injection molded. The thermal degradation and flammability of TKaol PMMA nanocomposites was compared to pure PMMA and also to PMMA nanocomposites filled with untreated Kaol. Results showed the influence of Kaol morphology on fire behavior of these nanocomposites. The use of exfoliated Kaol allowed a better thermal stability to be achieved and the decrease of peak heat release rate (PHRR) as revealed by the cone calorimeter tests. Moreover, TKaol PMMA nanocomposite enabled to maintain time to ignition close to that of PMMA while it was largely reduced with PMMA nanocomposites filled with untreated Kaol. Finally, exfoliated Kaol led to an efficient barrier effect due to the formation of a cohesive residue as highlighted by its mechanical strength.
\end{abstract}

Keywords:

Kaolinite

PMMA

Flame retardancy

Exfoliation

Nanocomposite

Cone calorimeter

\section{Introduction}

Poly(methyl methacrylate) (PMMA) is one of the most widely used thermoplastic but as it is a highly flammable polymer, its use in many applications is limited. During the past decade, the incorporation of organomodified layered silicates (OMt) into PMMA via melt blending or in situ polymerization has been investigated in order to improve its flammability (Huskic and Zigon, 2007; Kashiwagi et al., 2008; Laachachi et al., 2005; Qu et al., 2005; Sahoo and Samal, 2007; Wang et al., 2009, 2010a; Zheng et al., 2005; Zhu et al., 2002; Wang et al., 2009,2010a). Kiliaris and Papaspyrides (2010) showed that OMt improved the fire resistance of PMMA. The principal mechanism suggested was that the concentration of clay minerals at the surface of the sample increased during the thermal degradation of the polymer matrix acting as a barrier to insulate the material from heat and also from the diffusion of oxygen (Gilman et al., 2000).

Among the layered silicates, montmorillonite (Mt) has attracted special attention due to its swelling structure which facilitates their dispersion in PMMA (Wang et al., 2010b). However, kaolinite a non-swelling clay mineral received less attention. The exfoliation of Kaol was investigated by many research groups (Frost et al., 1998; Tsunematsu and Tateyama, 1999; Valášková et al., 2007; Vempati et al., 1996). The

\footnotetext{
* Corresponding author. Tel.: + 33 466785669; fax: + 33466785365. E-mail address: Belkacem.Otazaghine@mines-ales.fr (B. Otazaghine).
}

common point among all these studies was primarily intercalation of organic molecules in Kaol, which is expressed in increasing of its basal spacing. Furthermore, the increasing of basal spacing allowed the in situ polymerization of monomer between the basal internal surfaces of Kaol for reaching exfoliation. However, to the best of our knowledge, the use of exfoliated Kaol in PMMA in order to improve the fire behavior was never studied.

In the present work, the effect of intercalated Kaol as filler on fire behavior of PMMA is reported. First, the Kaol was intercalated using organic molecules. This obtained TKaol permits the preparation of an intercalated/exfoliated TKaol PMMA nanocomposite via in situ polymerization. The thermal degradation and flame resistance of this nanocomposite was investigated using TGA and cone calorimeter test.

\section{Materials and methods}

The Kaol used in this study was supplied by Prolab inc. Its specific surface area was found to be $12.2 \pm 0.3 \mathrm{~m}^{2} \cdot \mathrm{g}^{-1}$ (Brunauer-Emmett-Teller (B-E-T) method, using $\mathrm{N}_{2}$ as adsorbed gas on a Beckman Coulter SA3100 instrument). The median particle size $\left(\mathrm{d}_{50}\right)$ of Kaol obtained by laser particle-size analysis (Coulter LS230) was estimated to be around $3 \mu \mathrm{m}$. Two types of PMMA were used: a commercially available PMMA (Altuglas V825T) supplied by Arkema and a synthesized PMMA (synthesized via radical polymerization in our laboratory). Methyl methacrylate (MMA) was obtained by Aldrich. Azobisisobutyronitrile (AIBN) was used as initiator and was purchased from Fluka. Dimethyl sulfoxide (DMSO) (99\%, Fluka) and dodecylamine (Aldrich) were used. 


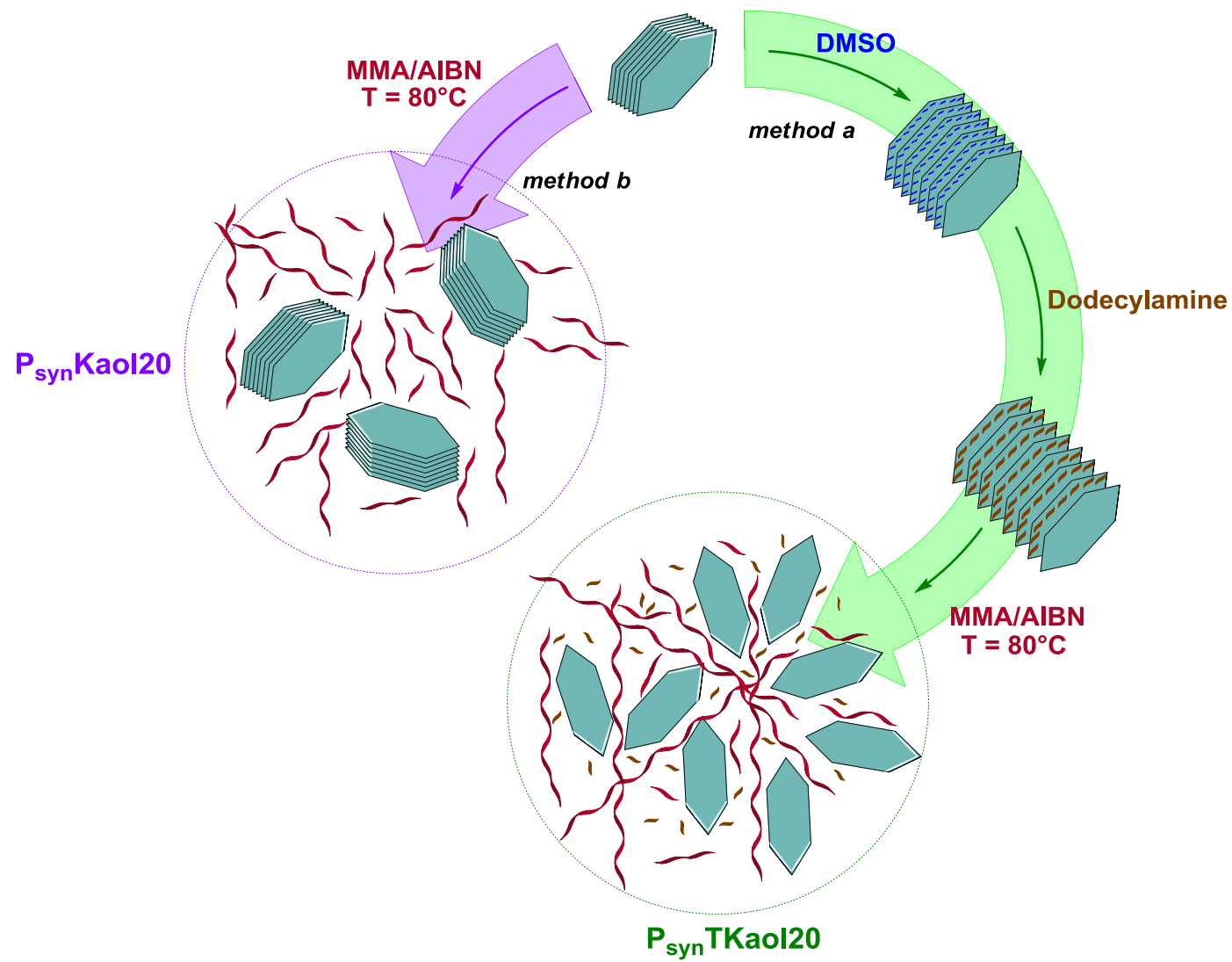

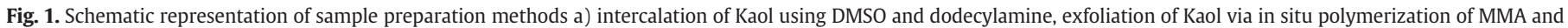
b) in situ polymerization of MMA with the non raw Kaol.

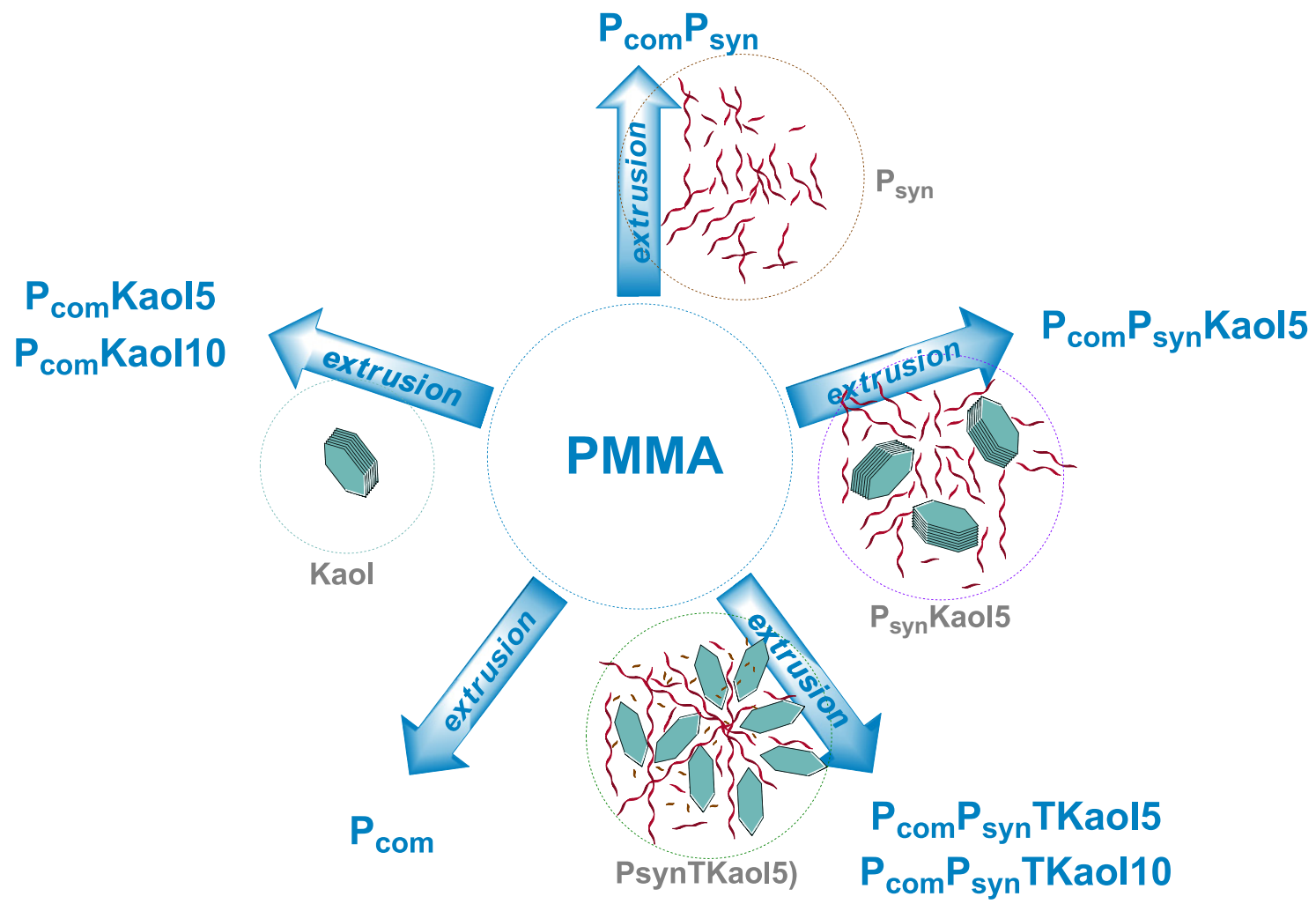

Fig. 2. Schematic representation of samples preparation. 
Table 1

Sample names and compositions $\left(\mathrm{P}_{\text {com }}=\right.$ PMMA Altuglas, $\mathrm{P}_{\text {syn }}=$ radical synthesized PMMA, Kaol $=$ kaolin, TKaol $=$ treated kaolin $)$.

\begin{tabular}{lllll}
\hline Sample code & Kaol (wt.\%) & TKaol (wt.\%) & $\mathrm{P}_{\text {syn }}$ (wt.\%) & $\mathrm{P}_{\text {com }}$ (wt.\%) \\
\hline $\mathrm{P}_{\text {com }}$ & - & - & - & 100 \\
$\mathrm{P}_{\text {com }} \mathrm{P}_{\text {syn }}$ & - & - & 25 & 75 \\
$\mathrm{P}_{\text {com Kaol5 }}$ & 5 & - & - & 95 \\
$\mathrm{P}_{\text {com Kaol10 }}$ & 10 & - & - & 90 \\
$\mathrm{P}_{\text {syn Kaol20 }}$ & 20 & - & - & 80 \\
$\mathrm{P}_{\text {syn }}$ TKaol20 & - & 20 & - & 80 \\
$\mathrm{P}_{\text {com }} \mathrm{P}_{\text {syn Kaol5 }}$ & 5 & - & 24 & 71 \\
$\mathrm{P}_{\text {com }} \mathrm{P}_{\text {syn }}$ TKaol5 & - & 5 & 24 & 71 \\
$\mathrm{P}_{\text {com }} \mathrm{P}_{\text {syn }}$ Kaol10 & 10 & - & 22.5 & 67.5 \\
$\mathrm{P}_{\text {com }} \mathrm{P}_{\text {syn }}$ TKaol10 & - & 10 & 22.5 & 67.5 \\
\hline
\end{tabular}

\subsection{Kaol treatment}

In the first step, the raw Kaol was intercalated with DMSO added in excess. The mixture was sonicated for $3 \mathrm{~h}$ at $70{ }^{\circ} \mathrm{C}$ using a Branson Sonifier (Branson Sonic-Power Company) operating at a frequency of $20 \mathrm{kHz}$ and a power of $550 \mathrm{~W}$. The mixture was then centrifuged (speed: $400 \mathrm{rpm}$ ) and washed three times with ethanol to remove the excess of DMSO. In the second step, the DMSO intercalated Kaol was treated by dodecylamine using the latter method (the final Kaol, after two steps of modification was named TKaol). The TKaol was then dried at $100{ }^{\circ} \mathrm{C}$ in a vacuum oven for $8 \mathrm{~h}$.

\subsection{In situ polymerization of MMA in Kaol}

Into a $500 \mathrm{~mL}$ flask fitted with a condenser, $100 \mathrm{~g}\left(9.99 \times 10^{-1} \mathrm{~mol}\right)$ of MMA, $1.64 \mathrm{~g}\left(9.99 \times 10^{-3} \mathrm{~mol}\right)$ of AIBN and $25 \mathrm{~g}$ of Kaol (Kaol/ $\mathrm{MMA}=25 \mathrm{wt} . \%$ ) were introduced. Argon was bubbled through the mixture for $15 \mathrm{~min}$. The flask was then placed in an oil bath previously heated at $60{ }^{\circ} \mathrm{C}$ for $2 \mathrm{~h}$. The same procedure was used for a mass ratio equal to 25 wt.\% and 50 wt.\%, with the intercalated Kaol to obtain exfoliated Kaol in a PMMA matrix (Fig. 1).

\subsection{Preparation of Kaol/PMMA nanocomposite}

The Kaol/PMMA samples were prepared via two different routes. The first route involved a melt blending step of PMMA with Kaol before the injection stage (Fig. 2). The second route comprised a preliminary step of polymerization of MMA in the presence of intercalated or nonintercalated Kaol (Fig. 1a-b). This step was followed by the melt blending of the obtained product with the commercial PMMA before the injection step. The melt blending was carried out on a co-rotating twin-screw extruder (Clextral, standard profile, length $=900 \mathrm{~mm}$, speed $=180 \mathrm{rpm}$, screw diameter $=20 \mathrm{~mm}, \mathrm{~T}=180{ }^{\circ} \mathrm{C}$ to $240{ }^{\circ} \mathrm{C}$ ). The samples were injection molded (Krauss Maffei KM $50 \mathrm{t}, \mathrm{T}=200-240{ }^{\circ} \mathrm{C}$, mold temperature $\left.=80^{\circ} \mathrm{C}\right)$ to obtain specimens $\left(100 \times 100 \times 4 \mathrm{~mm}^{3}\right)$. Sample pellets were dried at $70{ }^{\circ} \mathrm{C}$ for $8 \mathrm{~h}$ before injection molding. For both routes, reference samples were made without Kaol. The sample names and compositions are given in Table 1. Figs. 1 and 2 represent the different routes to obtain the final samples.

\subsection{Characterization}

The X-ray diffraction (XRD) patterns were recorded using a Bruker AXS D8 Advance diffractometer with $\mathrm{CuK} \alpha$ radiation and a Vantec detector. The scanning range was from $5^{\circ}$ to $30^{\circ}$ with a step size of $0.007^{\circ}$ and step time of $24.6 \mathrm{~s}$. All measurements were taken using a generator voltage of $40 \mathrm{kV}$ and a generator current of $40 \mathrm{~mA}$. The thermal decomposition was investigated using a Perkin Elmer Pyris-1 TGA. All measurements were performed under nitrogen and air with a heating rate of $10^{\circ} \mathrm{C} \cdot \mathrm{min}^{-1}$. The sample weight was $10 \pm 2 \mathrm{mg}$. A Scanning Electron Microscopy (FEI Quanta 200 SEM) was used to study the morphology of the samples. All images were obtained under high vacuum at a voltage of $25.0 \mathrm{kV}$ with a spot size of 2.8 and a working distance of $8.2 \mathrm{~mm}$. STEM (Scanning Transmission Electron Microscopy) measurements were performed using a TEM Jeol 1200EX2. The STEM crosssection samples were prepared with a cryo-ultramicrotom. The thickness of these samples varied in the range of 60 to $100 \mathrm{~nm}$. A cone calorimeter device (Fire Testing Technology) was used to evaluate the flammability of samples. Square specimen dimensions were $100 \times 100 \times 4 \mathrm{~mm}^{3}$ and

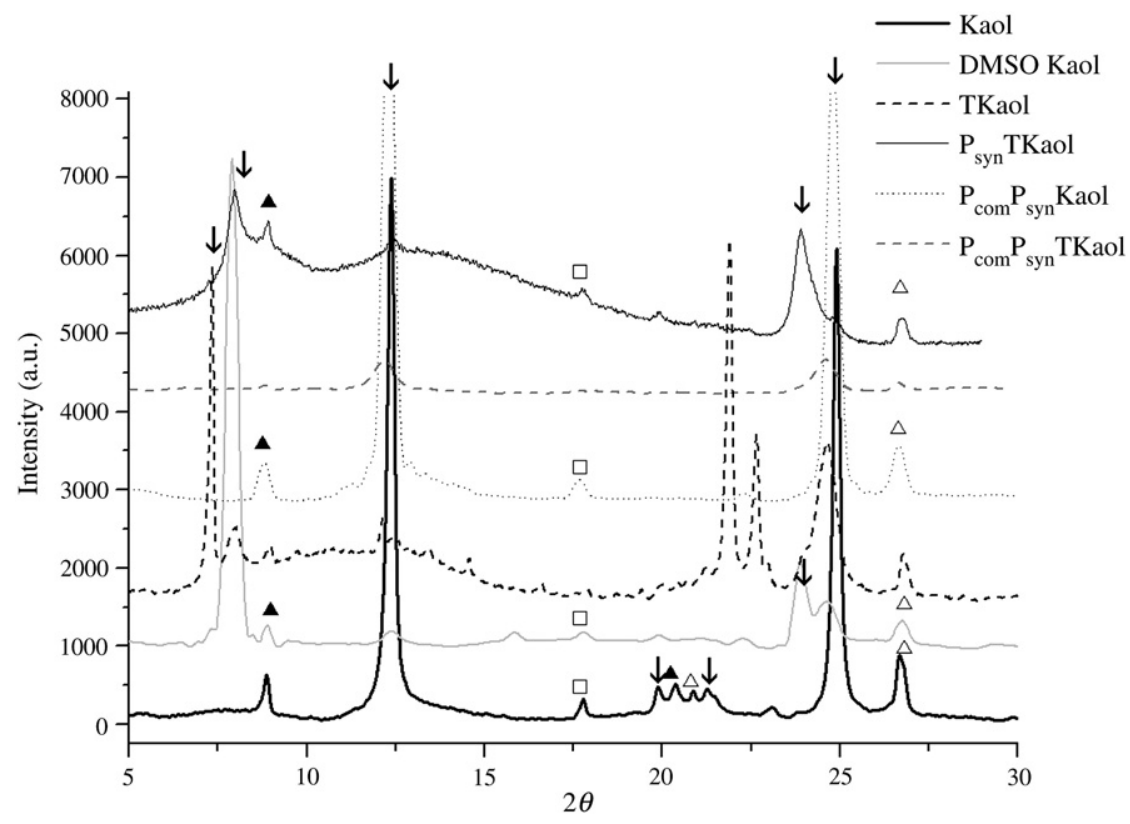

Fig. 3. X-ray diffractograms of raw kaol (a) and TKaol (b), $\downarrow$ : kaolin, $\Delta$ : silica, $\mathbf{\Delta}$ : alumino silicate $\left(\mathrm{Al}_{2} \mathrm{Si}_{2} \mathrm{O}_{5}(\mathrm{OH})_{4} 2 \mathrm{H}_{2} \mathrm{O}\right)$ and $\square$ : muscovite. 

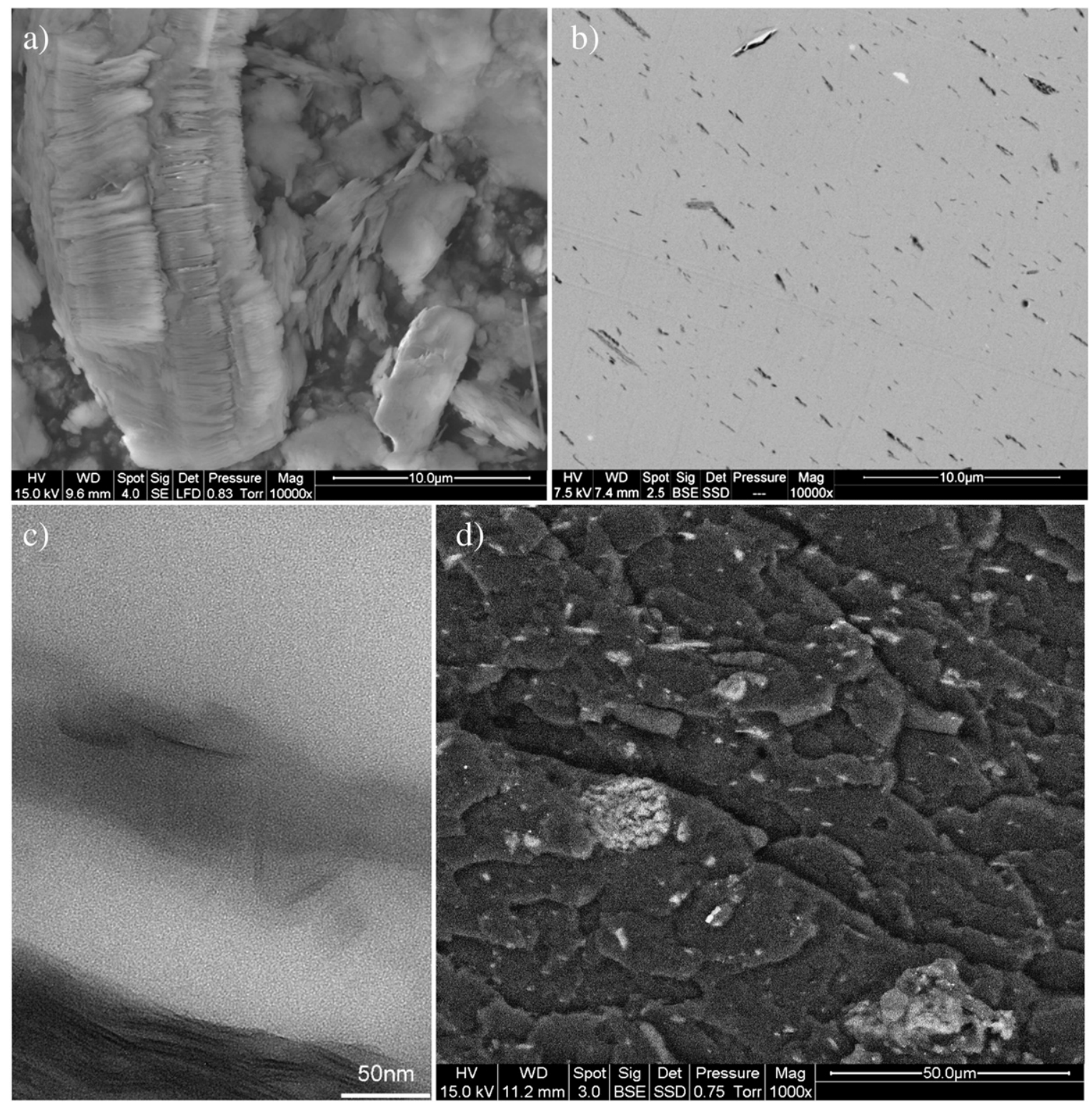

Fig. 4. SEM image of raw kaol (a) and STEM image of $\mathrm{P}_{\text {com }} \mathrm{P}_{\text {syn }}$ TKaol5 (b, c).

irradiated at a heat flux of $35 \mathrm{~kW} \cdot \mathrm{m}^{-2}$. All samples were characterized in duplicate. Uncertainty was estimated to be around $10 \%$.

The breaking resistance of residue was carried out using a compression tool, connected to a load cell of 10 daN capacity in an ADAMEL DY26 mechanical testing machine. The burned samples (char residue) were pressed by a cylindrical sensor with a diameter of $1 \mathrm{~mm}$ and the compression rate of $0.1 \mathrm{~mm} \cdot \mathrm{min}^{-1}$. The applied force $(\mathrm{N})$ to break down the residue was recorded using this apparatus (Fig. 12).

\section{Results and discussion}

\subsection{XRD analysis}

Fig. 3 displayed the XRD patterns of raw Kaol and TKaol. The $\mathrm{d}_{001}$-spacing for untreated Kaol was measured as $7.16 \AA$ (peak at $2 \theta=$ 12.37). The chemical treatment with DMSO and then with dodecylamine leads to a shift of this peak to $2 \theta=7.89(\mathrm{~d}=11.18 \AA)$ and $2 \theta=7.32(\mathrm{~d}=$ $12.05 \AA$ ), respectively. This increase indicated that DMSO and dodecylamine were intercalated into the interlayer space of Kaol. The

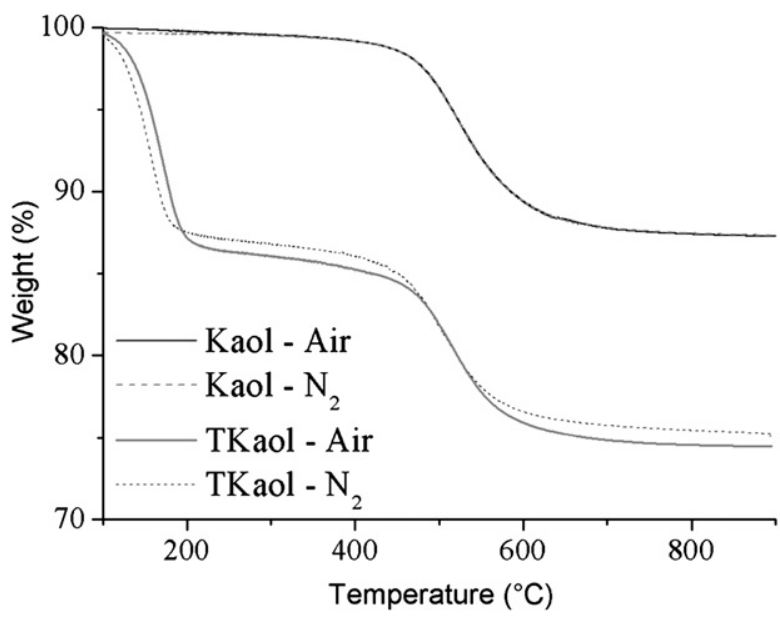

Fig. 5. Thermal stability of kaol before and after treatment under nitrogen and air. 


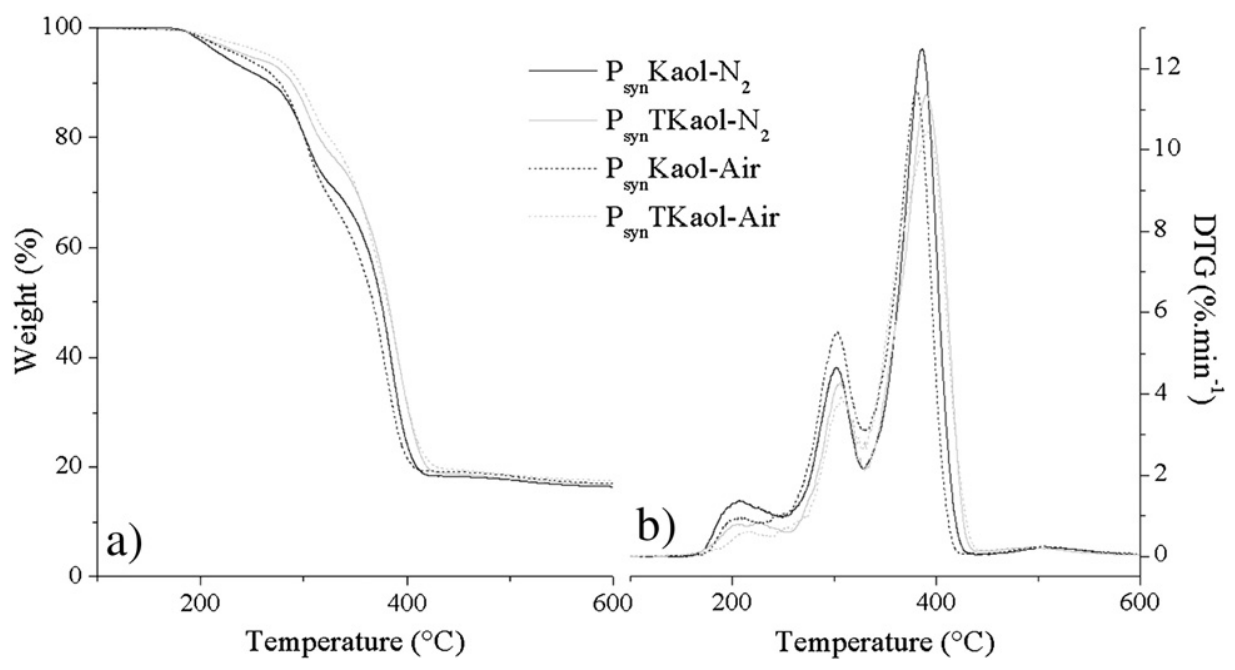

Fig. 6. TGA (a) and DTG (b) curves of $\mathrm{P}_{\text {syn }} \mathrm{Kaol}$ and $\mathrm{P}_{\text {syn }}$ TKaol at a heating rate of $10{ }^{\circ} \mathrm{C} \cdot \mathrm{min}^{-1}$ under nitrogen and air.

in situ polymerization of MMA shifted the peak of $\mathrm{d}_{001}$ to $2 \theta=7.89$ and the quasi absence of this peak in Pcom Psyn TKaol5 sample indicates a partially exfoliated state. The peaks presented in Pcom Psyn TKaol5 sample were due to some untreated Kaol already present in Psyn TKaol5. Similar results were observed for samples containing $10 \mathrm{wt}$ \% of Kaol.

\subsection{SEM and STEM}

Both SEM and STEM were used to determine the exfoliation of Kaol in PMMA matrix. Fig. 4 showed the SEM images of pristine Kaol (a) and STEM images of TKaol in PMMA (Pcom Psyn TKaol5) (b and c). The pristine Kaol presented stacked platelet structure around $20 \mu \mathrm{m}$.

The treatment procedure of Kaol permitted obtaining an intercalated and partially exfoliated morphology. The high-magnification STEM image of (Pcom Psyn TKaol5) sample was presented in Fig. 4c. From these images a small quantity of Kaol appeared to be not exfoliated and poorly dispersed in accordance with XRD that confirmed some non exfoliated Kaol (the presence of a small peak at $2=12.37$ for Pcom Psyn TKaol5 sample).

\subsection{TGA analysis}

The results of TGA and the corresponding derivative curves (DTG) for all samples shown in Figs. 5-8 were also summarized in Tables 2 and 3. The one step of degradation for raw Kaol corresponded to dehydroxylation around $450{ }^{\circ} \mathrm{C}$ (Wang et al., 2011). The two steps of degradation for TKaol around $125^{\circ} \mathrm{C}$ and $450{ }^{\circ} \mathrm{C}$ is due to i) degradation of organic molecules (confirming the intercalation of DMSO and dodecylamine) and ii) dehydroxylation. The thermal degradation of raw Kaol in air also occurred in one step of weight loss around $450{ }^{\circ} \mathrm{C}$ (Fig. 5).

After in situ polymerization of PMMA with TKaol and raw Kaol, the TGA of these samples showed the stabilization effect of TKaol compared to untreated Kaol (Fig. 6).

All composite and polymer samples appeared to be degraded in one step. Only the samples with 5 wt.\% of TKaol (Pcom Psyn TKaol5) showed an improvement in thermal stability and a more slightly degradation rate up to $400{ }^{\circ} \mathrm{C}$ (under air and nitrogen). The residue percentage was stabilized after $430{ }^{\circ} \mathrm{C}$ for all samples (Figs. 7 and 8 ).

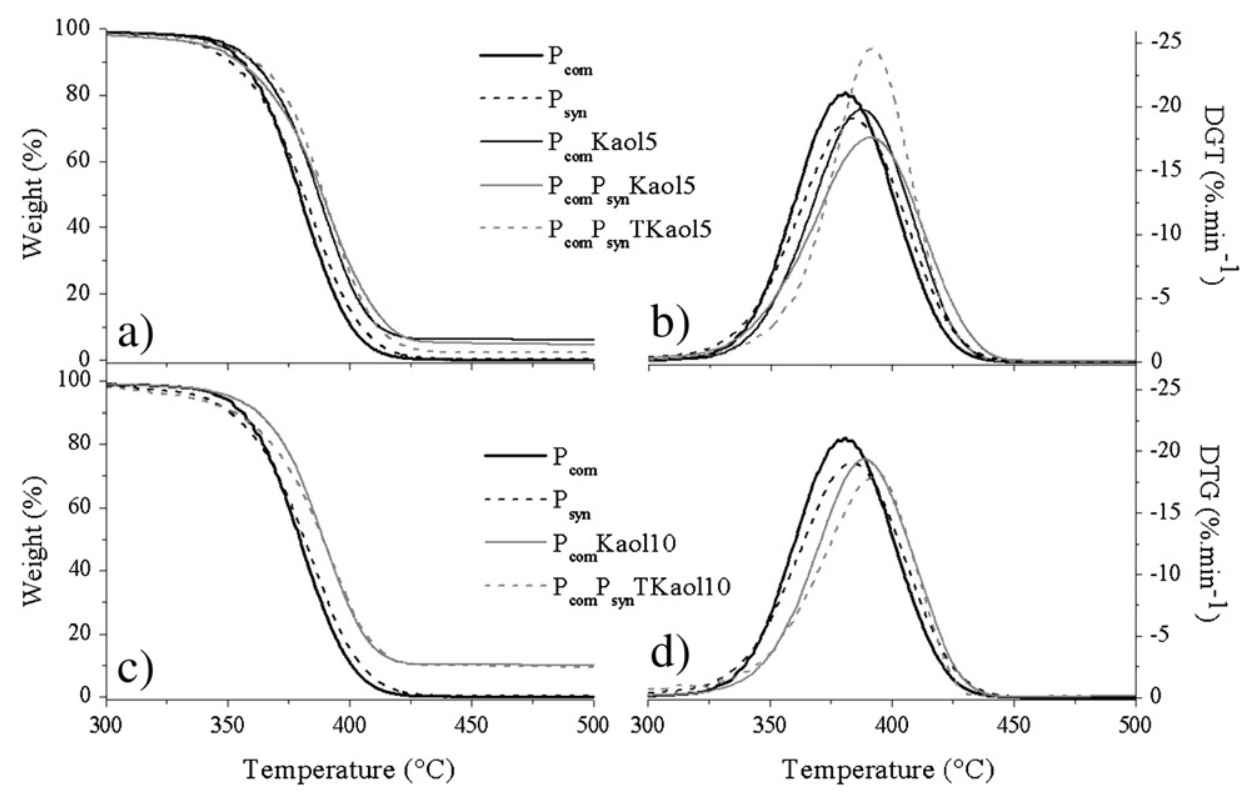

Fig. 7. TGA (a, c) and DTG (b, d) curves at a heating rate of $10{ }^{\circ} \mathrm{C} \cdot \mathrm{min}^{-1}$ under nitrogen. 


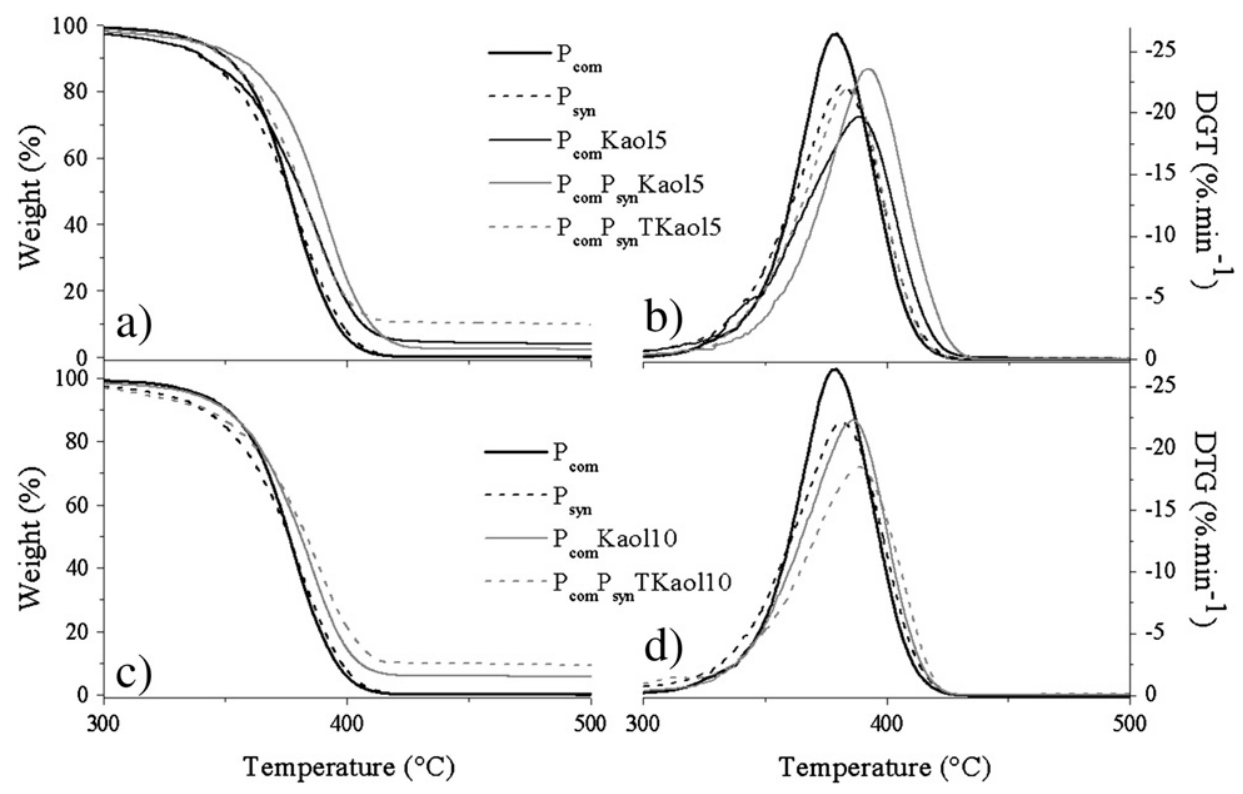

Fig. 8. TGA (a, c) and DTG (b, d) curves at a heating rate of $10{ }^{\circ} \mathrm{C} / \mathrm{min}$ under air.

The Pcom Psyn TKaol10 sample exhibited a lower thermal stability than Pcom Psyn TKaol5 up to $410{ }^{\circ} \mathrm{C}$ (under nitrogen and air). This can be ascribed to the presence of more important quantity of DMSO and dodecylamine. The residue percentages were proportional to incorporated Kaol for all samples. In other words, the exfoliation of Kaol did not promote the charring residues which correspond to essentially initial Kaol.

\subsection{Cone calorimeter test}

The fire resistance of the samples was studied using cone calorimeter test with an incident flux of $35 \mathrm{~kW} \cdot \mathrm{m}^{-2}$. It is well known that an important quantity of samples was needed in this kind of test. Therefore, the primary tests were performed only on the samples containing $10 \mathrm{wt} . \%$ of Kaol. The heat release rate (HRR) curves as a function of time were shown in Fig. 9a while the time to ignition (TI), the peak of heat release rate (PHRR) and the total heat release (THR) of the samples were summarized in Table 4.

It is noteworthy that TI decreased for nanocomposites containing Kaol. The presence of fillers may modify the absorbance of the samples in the infrared region. Therefore, a larger part of the radiations emitted by the cone was absorbed within the upper layer of nanocomposites leading to a rapid heating of the sample surface and thus to a smaller TI (Yu et al., 2009). It should be noticed that the formulation containing exfoliated Kaol exhibited a higher TI close to that of pure PMMA.

The HRR peak decreased for nanocomposites containing Kaol. The treatment of Kaol had also a positive effect, since TKaol/PMMA 10 wt.\% presented an extended form (after $310 \mathrm{~s}$ ) as a function of time compared to the other nanocomposites. It could be observed that the quantity of residue corresponded roughly to the content of Kaol after dehydration. Therefore, the presence of fillers did not promote charring.

The weight loss curves obtained as a function of time for the various formulations were presented in Fig. 9b. A significant reduction of mass loss rate was observed for the samples containing $10 \mathrm{wt}$.\% of Kaol (treated or not). However, this reduction was more pronounced in the case of TKaol. Decrease of mass loss rate resulted either from a higher thermal stability of the formulation or from the formation of a barrier during combustion.

The photos of the residues collected after cone calorimeter tests (Fig. 10) showed that the samples containing the PMMA nanocomposites with TKaol presented a better cohesion compared to those samples containing raw Kaol. These residues were also observed by SEM (Fig. 11). Fig. 11a corresponding to the sample with TKaol clearly showed exfoliated Kaol particles whereas in the case of sample containing raw Kaol (Fig. 11b) a stacked morphology was observed. It appears that during combustion TKaol platelets did not re-aggregate.

Laoutid et al. (2006a) suggested that the breaking resistance of char residue was related to their cohesion and therefore contributed to the flame retardancy. Cohesion of residues was assessed using a mechanical compression test as described in the Materials and methods section (Fig. 12). The compressive strength of Pcom Psyn Kaol10 and Pcom Psyn TKaol10 residues was characterized. The maximum forces measured to break down the residue were $0.09 \pm 0.03 \mathrm{~N}$ and $0.20 \pm$ $0.05 \mathrm{~N}$ for Pcom Psyn Kaol10 and Pcom Psyn TKaol10, respectively.
Table 2

TGA parameters under nitrogen atmosphere.

\begin{tabular}{llll}
\hline Composition & $\mathrm{T}_{10 \%}\left({ }^{\circ} \mathrm{C}\right)$ & $\mathrm{T}_{50 \%}\left({ }^{\circ} \mathrm{C}\right)$ & Residue\% \\
\hline Raw kaol & 580 & - & 87.2 \\
$\mathrm{P}_{\text {syn Kaol20 }}$ & 265 & 375 & 16 \\
$\mathrm{P}_{\text {syn }}$ TKaol20 & 288 & 382 & 16.6 \\
$\mathrm{P}_{\text {com }}$ & 356 & 379 & 0 \\
$\mathrm{P}_{\text {com }} \mathrm{P}_{\text {syn }}$ & 350 & 381 & 0 \\
$\mathrm{P}_{\text {com }} \mathrm{P}_{\text {syn }}$ Kaol5 & 355 & 389 & 5 \\
$\mathrm{P}_{\text {com Kaol5 }}$ & 360 & 387 & 5.8 \\
$\mathrm{P}_{\text {com }} \mathrm{P}_{\text {syn }}$ TKaol5 & 364 & 394 & 2.4 \\
$\mathrm{P}_{\text {com Kaol10 }}$ & 362 & 389 & 10 \\
$\mathrm{P}_{\text {com }} \mathrm{P}_{\text {syn }}$ TKaol10 & 352 & 389 & 9.5 \\
\hline
\end{tabular}

a Residue at $900{ }^{\circ} \mathrm{C}$
Table 3

TGA parameters under air atmosphere.

\begin{tabular}{llll}
\hline Composition & $\mathrm{T}_{10 \%}\left({ }^{\circ} \mathrm{C}\right)$ & $\mathrm{T}_{50 \%}\left({ }^{\circ} \mathrm{C}\right)$ & Residue $(\%)^{\mathrm{a}}$ \\
\hline Raw kaol & 580 & - & 87.2 \\
$\mathrm{P}_{\text {syn }}$ Kaol20 & 275 & 367 & 16.5 \\
$\mathrm{P}_{\text {syn }}$ TKaol20 & 295 & 380 & 17 \\
$\mathrm{P}_{\text {com }}$ & 350 & 375 & 0 \\
$\mathrm{P}_{\text {com }} \mathrm{P}_{\text {syn }}$ & 340 & 375 & 0 \\
$\mathrm{P}_{\text {com }} \mathrm{P}_{\text {syn }}$ Kaol5 & 342 & 381 & 3.6 \\
$\mathrm{P}_{\text {com Kaol5 }}$ & 350 & 381 & 5.2 \\
$\mathrm{P}_{\text {com }} \mathrm{P}_{\text {syn }}$ TKaol5 & 355 & 387 & 2.2 \\
$\mathrm{P}_{\text {com Kaol10 }}$ & 350 & 381 & 9 \\
$\mathrm{P}_{\text {com }} \mathrm{P}_{\text {syn }}$ TKaol10 & 343 & 383 & 8.6 \\
\hline
\end{tabular}

\footnotetext{
a Residue at $900{ }^{\circ} \mathrm{C}$.
} 

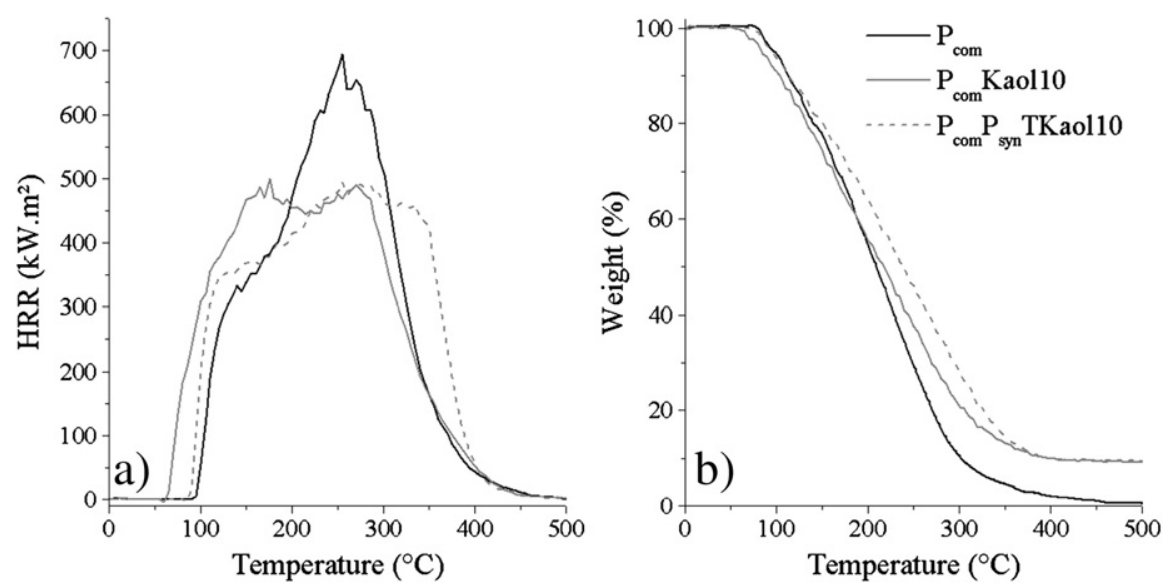

Fig. 9. HRR curves (a) and weight loss curves (b) under an incident heat flux of $35 \mathrm{~kW} \cdot \mathrm{m}^{-2}$

Table 4

Cone calorimetric data for PMMA and its nanocomposites under a heat flux of $35 \mathrm{~kW} \cdot \mathrm{m}^{-2}$.

\begin{tabular}{lllll}
\hline Sample & TI $(\mathrm{s})$ & Peak HRR $\left(\mathrm{kW} \cdot \mathrm{m}^{-2}\right)$ & THR $\left(\mathrm{MJ} \cdot \mathrm{m}^{-2}\right)$ & Residue (wt.\%) \\
\hline PMMA & 95 & 691 & 124 & 0 \\
$\mathrm{P}_{\text {com Kaol10 }}$ & 62 & 496 & 115 & 9.3 \\
$\mathrm{P}_{\text {com }} \mathrm{P}_{\text {syn }}$ TKaol10 & 85 & 488 & 117 & 9.3 \\
\hline
\end{tabular}

Although the char geometries were not completely identical, the large difference between both obtained values indicated a significant difference in the mechanical strength of the residues and thus in their cohesion.

It was reported that the presence of clay mineral generated a positive effect on flame retardancy of some polymers (Kiliaris and Papaspyrides, 2010). Some factors such as the size of clay mineral, clay mineral dispersion, rate of exfoliation and uniformity of the char influenced the fire behavior of composites. Moreover, it was highlighted that a critical
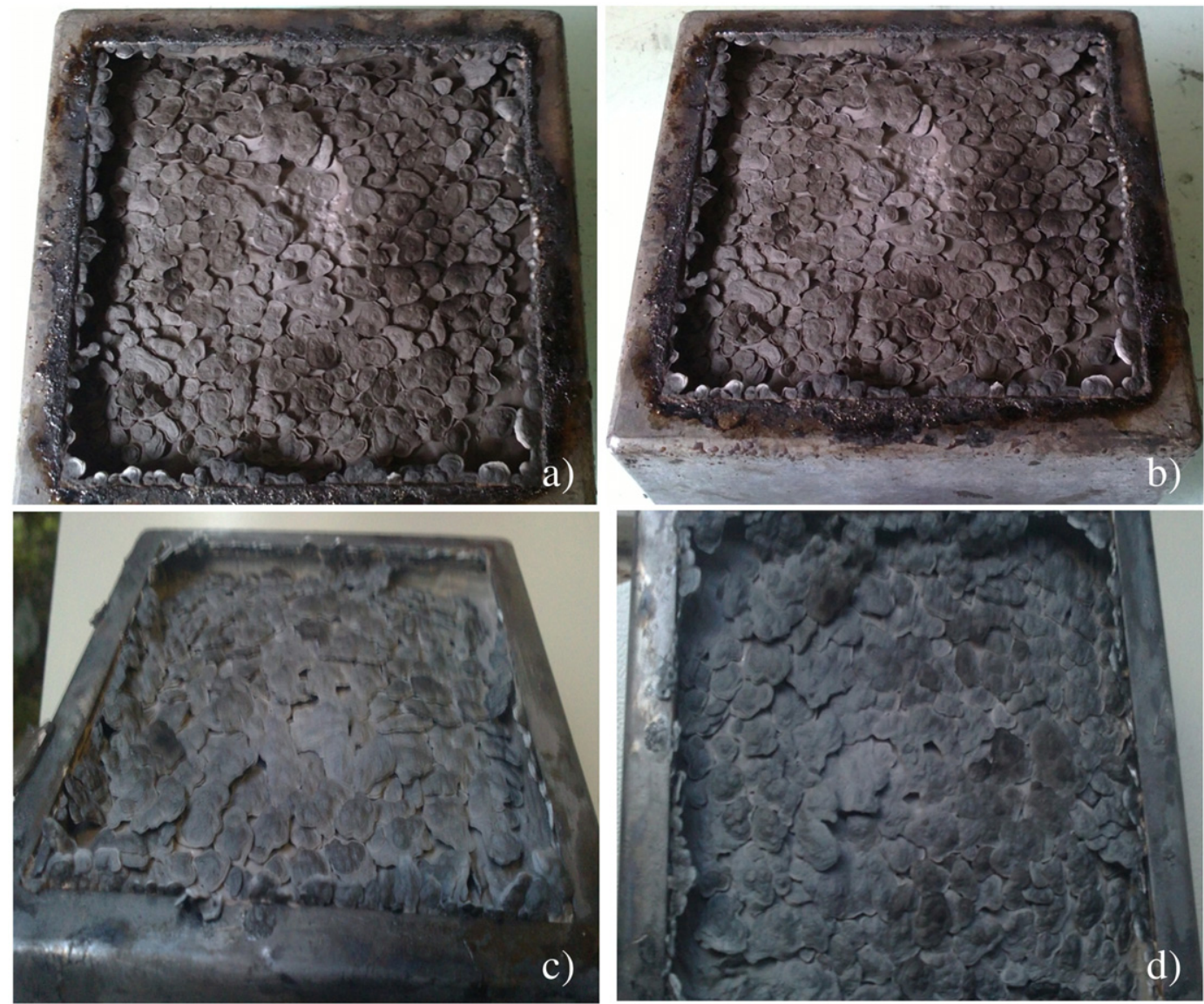

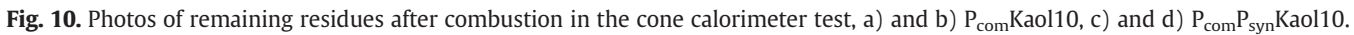



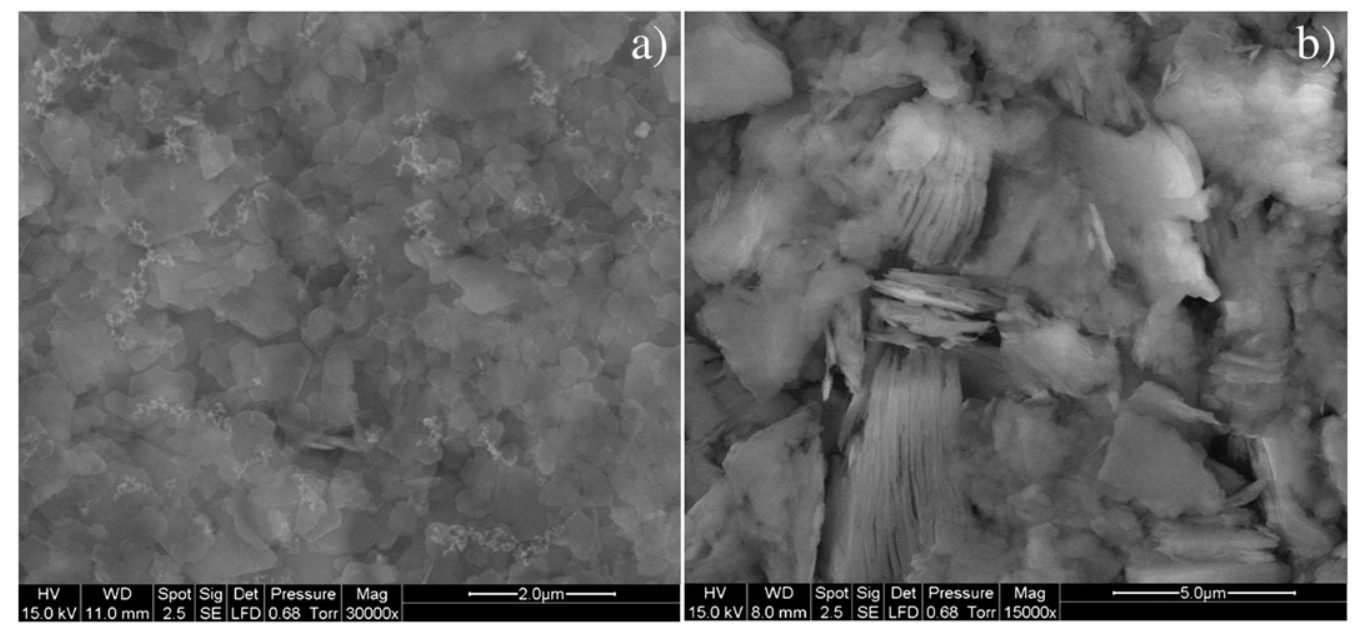

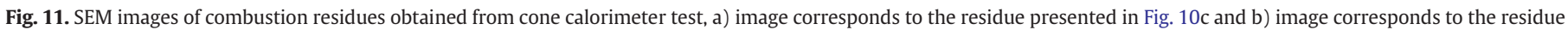
presented in Fig. 10a.

threshold of clay mineral percentage was needed to form a stable residue with no cracks (Dasari et al., 2007). In the present study, the TKaol (10 wt.\%) partially provided the above-described conditions. During combustion the exfoliated Kaol platelets accumulated at the sample surface according to the two possible mechanisms described by Kashiwagi et al. (2004) either by polymer recession leaving the platelets at the surface or by migration under the action of the rising bubbles of degradation products. Since the aspect ratio of exfoliated Kaol platelets was much higher than that of the raw particles, the covering ability of these platelets was much higher as well. Therefore, exfoliated particles likely formed more easily a cohesive layer at the sample surface (Fig. 13). Hence, the decrease of PHRR and the extension of HRR curve to longer times, in the case of TKaol, were attributed to the formation of a cohesive residue that played the role of physical barrier for heat and mass transfer (Laoutid et al., 2006b).

Nevertheless, even if TKaol induced a positive effect of fire properties of PMMA, the combination with current flame retardant (such as phosphorus flame retardant) will be necessary to obtain an acceptable fire rating (Yang and Nelson, 2011). Furthermore, these results showed

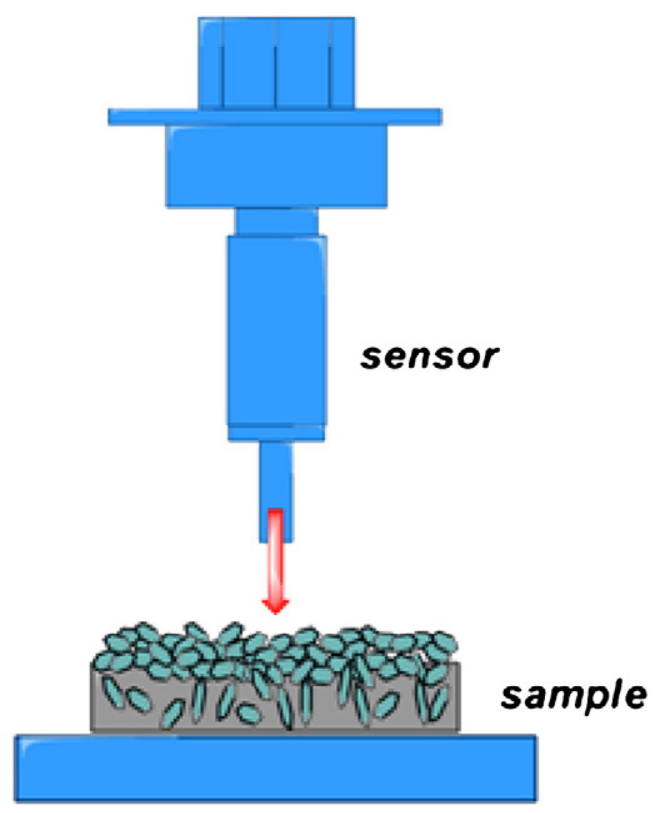

Fig. 12. ADAMEL DY26 mechanical test. that Kaol was not as efficient as Mt for improving the flammability of PMMA.

\section{Conclusion}

The effect of Kaol on thermal degradation and flame retardancy of PMMA was investigated. The Kaol/PMMA nanocomposites were prepared using two successive routes to obtain exfoliated or not exfoliated morphology (in situ polymerization and/or extrusion). After an intercalation procedure for the clay mineral, the in situ polymerization of MMA between the Kaol layers led to an exfoliated morphology. The Kaol/PMMA nanocomposites containing the exfoliated Kaol presented a better thermal stability in TGA analysis compared to the samples with non exfoliated Kaol. According to cone calorimeter tests, the nanocomposites containing exfoliated Kaol also showed an improvement of the fire behavior with a higher TI close to that of pure PMMA. The exfoliation of Kaol reinforced the residue during the combustion, leading to a better flame behavior.

\section{Acknowledgment}

The authors would like to thank Mr. Marc Longerey for his assistance in mechanical testing, Mr. Sylvain Buonomo for injection molding and Mr. Jean-Marie Taulemesse for microscopy analysis. We are most grateful to Arkema for providing the PMMA.

\section{References}

Dasari, A., Yu, Z.Z., Mai, Y.W., Liu, S., 2007. Flame retardancy of highly filled polyamide 6/clay nanocomposites. Nanotechnology 18, 445602.

Frost, R.L., Kristof, J., Paroz, G.N., Kloprogge, J.T., 1998. Molecular structure of dimethyl sulfoxide intercalated kaolinites. The Journal of Physical Chemistry. B 102, 8519-8532.

Gilman, J.W., Jackson, C.L., Morgan, A.B., Harris Jr., R., Manias, E., Giannelis, E.P., Wuthenow, M., Hilton, D., Phillips, S.H., 2000. Flammability properties of polymer-layered-silicate nanocomposites. Polypropylene and polystyrene nanocomposites. Chemistry of Materials $12,1866-1873$.

Huskic, M., Zigon, M., 2007. PMMA/MMT nanocomposites prepared by one-step in situ intercalative solution polymerization. European Polymer Journal 43, 489-4897.

Kashiwagi, T., Harris Jr., R.H., Zhang, X., Briber, R.M., Cipriano, B.H., Raghavan, S.R., Awad, W.H., Shields, J.R., 2004. Flame retardant mechanism of polyamide 6-clay nanocomposites. Polymer 45, 881-891.

Kashiwagi, T., Mu, M., Winey, K., Cipriano, B., Raghavan, S.R., Pack, S., Rafailovich, M., Yang Y., Grulke, E., Shields, J., Harris, R., Douglas, J., 2008. Relation between the viscoelastic and flammability properties of polymer nanocomposites. Polymer 49, 4358-4368.

Kiliaris, P., Papaspyrides, C.D., 2010. Polymer/layered silicate (clay) nanocomposites: an overview of flame retardancy. Progress in Polymer Science 35, 902-958.

Laachachi, A., Leroy, E., Cochez, M., Ferriol, M., Lopez Cuesta, J.M., 2005. Use of oxide nanoparticles and organoclays to improve thermal stability and fire retardancy of poly(methyl methacrylate). Polymer Degradation and Stability 89, 344-352. 
a)

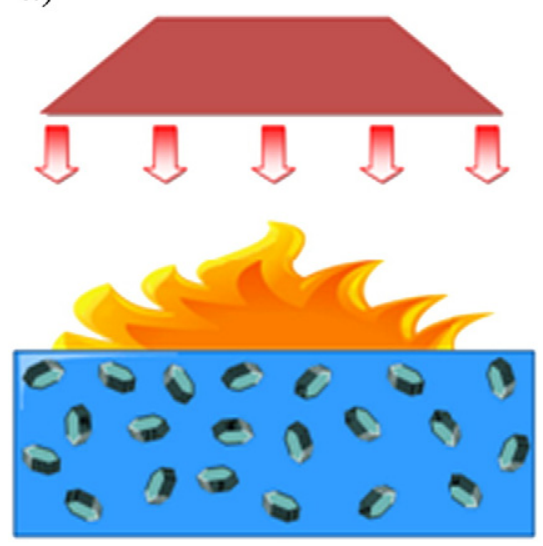

b)

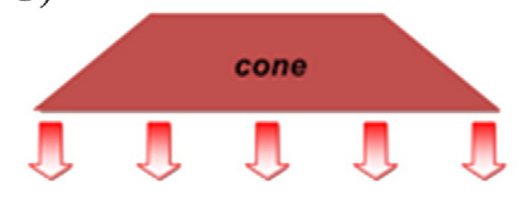

sample

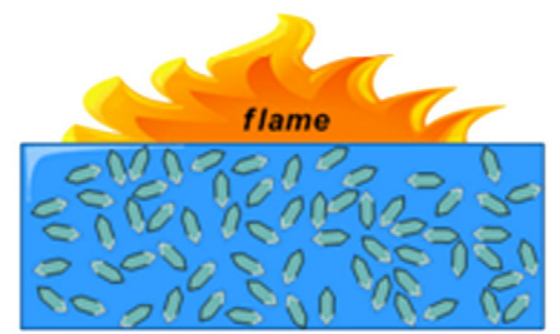

Side viow
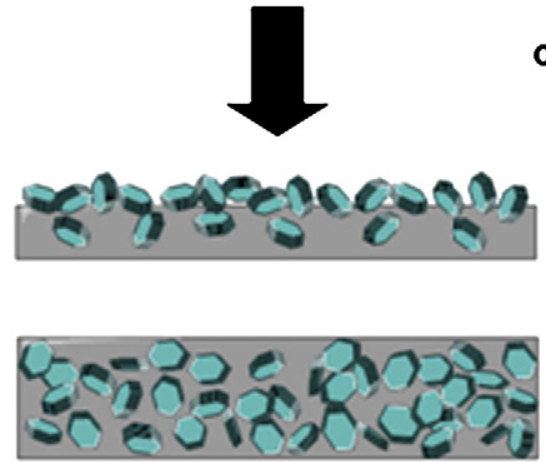

\section{Cone calorimeter test}

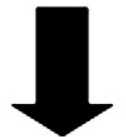

char residue

\section{Side view}

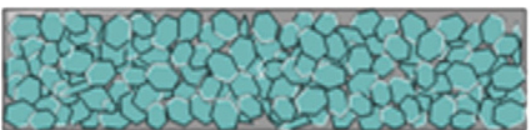

Top viow

Fig. 13. Schematic representation of residue formation during cone calorimeter test, sample containing raw Kaol (a) and TKaol (b).

Laoutid, F., Ferry, L., Leroy, E., Lopez Cuesta, J.M., 2006a. Intumescent mineral fire retardant systems in ethyleneevinyl acetate copolymer: effect of silica particles on char cohesion. Polymer Degradation and Stability 91, 2140-2145.

Laoutid, F., Gaudon, P., Taulemesse, J.M., Lopez Cuesta, J.M., Velasco, J.I., Piechaczyk, A., 2006b. Study of hydromagnesite and magnesium hydroxide based fire retardant systems for ethylenevinyl acetate containing organo-modified montmorillonite. Polymer Degradation and Stability 91, 3074-3082.

Qu, X., Guan, T., Liu, G., She, Q., Zhang, L., 2005. Preparation, structural characterization, and properties of poly(methyl methacrylate)/montmorillonite nanocomposites by bulk polymerization. Journal of Applied Polymer Science 97, 348-357.

Sahoo, P.K., Samal, R., 2007. Fire retardancy and biodegradability of poly(methyl methacrylate)/montmorillonite nanocomposite. Polymer Degradation and Stability 92, 1700-1707.

Tsunematsu, K., Tateyama, H., 1999. Delamination of urea-kaolinite complex by using intercalation procedures. Journal of the American Ceramic Society 82, 1589-1591.

Valášková, M., Rieder, M., Matějka, V., Čapková, P., Slíva, A., 2007. Exfoliation/delamination of kaolinite by low-temperature washing of kaolinite-urea intercalates. Applied Clay Science 35, 108-118.

Vempati, R.K., Mollah, M.Y.A., Reddy, G.R., Cocke, D.L., Lauer, H.V., 1996. Intercalation of kaolinite under hydrothermal conditions. Journal of Materials Science 31, 1255-1259.

Wang, L., Su, S., Chen, D., Wilkie, C.A., 2009. Fire retardancy of bis[2-(methacryloyloxy) ethyl] phosphate modified poly(methyl methacrylate) nanocomposites containing layered double hydroxide and montmorillonite. Polymer Degradation and Stability $94,1110-1118$.

Wang, L., Xie, X., Su, S., Feng, J. Wilkie, C.A., 2010a. A comparison of the fire retardancy of poly(methyl methacrylate) using montmorillonite, layered double hydroxide and kaolinite. Polymer Degradation and Stability 95, 572-578.

Wang, L., He, X., Wilkie, C.A., 2010b. The utility of nanocomposites in fire retardancy. Materials 3, 4580-4606.

Wang, H., Li, C., Peng, Z., Zhang, S., 2011. Characterization and thermal behavior of kaolinite. Journal of Thermal Analysis and Calorimetry http://dx.doi.org/10.1007/ s10973-011-1385-0.

Yang, F., Nelson, G.L., 2011. Combination effect of nanoparticles with flame retardants on the flammability of nanocomposites. Polymer Degradation and Stability 96, 270-276.

Yu, H., Xu, G., Shen, X., Yan, X., Shao, C., Hu, C., 2009. Effects of size, shape and floatage of Cu particles on the low infrared emissivity coatings. Progress in Organic Coatings 66, $161-166$.

Zheng, X., Jiang, D.D., Wilkie, C.A., 2005. Methyl methacrylate oligomerically-modified clay and its poly (methyl methacrylate) nanocomposites. Thermochimica Acta 435, 202-208.

Zhu, J., Start, P., Mauritz, K.A., Wilkie, C.A., 2002. Thermal stability and flame retardancy of PMMA-clay nanocomposites. Polymer Degradation and Stability 77, 253-258. 